\title{
ARTIGOS
}

\section{O BULLYING ESCOLAR NO BRASIL: REFLEXÕES GENDRADAS E A EMERGÊNCIA DE OLHARES INTERSECIONAIS}

Almerson Cerqueira Passos ${ }^{1}$

Resumo: O Bullying começou a ser estudado na Suécia, na década de 1970. É conceituado como um conjunto de comportamentos agressivos, físicos ou psicológicos, como humilhar, chutar, empurrar, apelidar, discriminar, isolar e excluir, ocorrendo de forma intencional e repetitiva. No Brasil, onde várias estruturas se articulam entre si, como o racismo, a homofobia, transfobia, lesbofobia, misoginia, lançar um olhar sobre qualquer tipo de violência sem uma proposta interseccional pode incidir na invisibilização dos sofrimentos psíquicos de estudantes que são diariamente atravessados por esses eixos de opressão. Se a escola tem responsabilidade na produção e desenvolvimento de novos cidadãos e cidadãs para a sociedade, trazendo no bojo dos seus planos pedagógicos a prioridade no combate às violências e o fomento da consciência e importância do respeito e da diferença, precisamos questionar qual o modelo de educação é viável para romper com a desigualdade e assimetrias de gênero, raça, sexualidade e outros marcadores identitários. O interesse por esse estudo é uma tentativa de compreensão do bullying a partir de uma perspectiva gendrada e interseccional, questionando produções científicas nacionais que articulam os estudos sobre esse fenômeno escolar e gênero, na sua maioria, ainda com uma lógica dicotômica do sexo biológico.

Palavras-chave: bullying escolar, gênero, interseccional, raça, sexualidade.

\section{Introdução}

A educação sempre foi a via pela qual se propunha uma possibilidade de transformação social, caminho real para as pessoas agirem mais criticamente frente ao mundo. Mas, infelizmente, tais valores não seguem os padrões de conduta em prol do respeito entre as diferenças. Debruçar-se sobre a escola e compreender o bullying escolar e seus mecanismosrevelará atitudes segregacionistas, de elevada intolerância, preconceito, violência e discriminação (DINIS, 2008).

\footnotetext{
${ }^{1}$ Psicólogo pela Universidade Salvador - UNIFACS. Especialista em Docência do Ensino Superior pela Universidade Salvador. Mestrando pelo Programa de Pós Graduação em Estudos Interdisciplinares sobre Mulheres, Gênero e Feminismo, pela Universidade Federal da Bahia (2018). Membro do grupo de pesquisa sobre Gênero e Sexualidade na Escola, pelo Núcleo de Pesquisa e Extensão em Culturas, Gêneros e Sexualidades (NuCus/UFBA), e do Grupo de Estudos Feministas em Política e Educação (GIRA/UFBA). Tem interesse por pesquisas em Gênero, Sexualidades, Educação, Raça, Cultura e Psicologia
} 
Segundo Maria José Martins (2005), vários estudos têm investigado conceitos que articulem a violência escolar e seus desdobramentos em todo o mundo. $\mathrm{O}$ tema da violência escolar foi estudado inicialmente na Europa a partir da necessidade de reestruturação de alguns países como a Alemanha, nas décadas de 1950 e 1960, palco de um dos maiores genocídios que a humanidade já presenciou e realizou.

No Brasil, os estudos da violência escolar partem da análise das depredações e danos aos prédios escolares e chega ao final da década de 1990 e início dos anos 2000 com o estudo das relações interpessoais agressivas, envolvendo alunos (as), professores (as) e outros agentes da comunidade escola (SPOSITO, 2001). Nessa perspectiva, em uma época onde as manifestações de violência estão cada vez mais explícitas na sociedade, falar sobre o bullying escolar e seus desdobramentos aparece como cenário importante de análise e combate aos sistemas de opressões que se intercruzam para a manutenção de comportamentos hegemônicos e historicamente construídos.

De acordo com Lisiane de Oliveira-Minegotto, Audri Pasini e Gabriel Levandowski (2013), o bullying começou a ser estudado na Suécia, na década de 1970. É conceituado como um conjunto de comportamentos agressivos, físicos ou psicológicos, como humilhar, chutar, empurrar, apelidar, discriminar, isolar e excluir, ocorrendo de forma intencional e repetitiva. No Brasil, o tema começou a ser discutido mais recentemente por volta de 1990, mas as produções científicas emergiram a partir de 2005. O marco que proporcionou maior visibilidade ao bullying foi o episódio no Columbine High School, ocorrido em 1999, nos Estados Unidos, em que dois alunos mataram 12 estudantes e um professor. Essa tragédia convocou autoridades governamentais, estudiosos (as) e pesquisadores (as) a traçarem maiores investigações sobre a dinâmica da violência escolar e os efeitos nocivos do bullying na autoestima dos (as) estudantes.

Estudiosos (DE OLIVEIRA-MINEGOTTO; PASINI; LEVANDOWSKI, 2013; FONSECA et al., 2012; BANDEIRA; HUTZ, 2012) vão dizer que existem várias classificações para o bullying. Ele pode ser classificado em direto, que são através dos atos físicos e verbais, ocorrendo quando as vítimas são atacadas diretamente pelos (as) agressores (as). Geralmente, esse tipo de bullying é mais praticado pelos meninos, manifestando-se em agressões por apelidos, agressões físicas, ameaças e roubos.

O bullying também pode acontecer indiretamente, caracterizado por agressões psicológicas, atitudes de indiferença, isolamento e difamação, sendo praticado de maneira equilibrada tanto pelos meninos quanto por meninas. Enquanto perfil de vítimas, os meninos 
também apresentam um percentual significativo talvez por estarem mais envolvidos nesses episódios; as meninas apresentam mais um perfil de vítimas do que agressoras. Todavia, essa divisão entre pares não define exatamente os perfis e não traça um panorama universal a cerca desse fenômeno. Qualquer um (a) deles (as) pode ser agressor (a), vítima, vítima/agressor ou testemunha, e isso dependerá do contexto, da cultura e da geopolítica de cada lugar. O que se sabe, de um modo geral, é que o bullying está mais presente entre os meninos e pensar os possíveis atravessamentos dessa realidade caracteriza um dos objetivos dessa pesquisa.

Enquanto perspectiva histórica e institucional, a violência sempre atravessou a humanidade através das relações de dominação e subordinação, interpeladas pelas estruturas de poder hegemônicas. Dessa maneira, o bullying pode ser entendido enquanto fenômeno social complexo que ocorre em todo o mundo, pela própria natureza da violência, resultante de inúmeros fatores identificados nas diversas relações desiguais de poder (FONSECA et al., 2012).

Todos os dias, episódios de violência escolar acontecem, alargando as estatísticas de sofrimento psíquico das vítimas envolvidas, levando-as, algumas vezes, ao ato suicida. Tratase de um problema global que atravessa a vida de milhares de jovens e nos convoca a combater esse tipo de violência que marca diversos corpos e identidades, principalmente aqueles que não estão dentro de um modelo social e politicamente estabelecido. A escola, enquanto aparelho do Estado traz, no bojo das suas matrizes curriculares, uma ideologia de civilidade que não permite que os (as) sujeitos (as) exerçam os seus desejos e performatividades de acordo com as suas sensações e convicções (MISKOLCI, 2012).

A produção de narrativas patologizantes, misóginas, sexistas, homofóbicas, lesbofóbicas, transfóbicas e racistas se intercruzam, constituindo um modelo de ensino educacional opressor que autoriza exclusivamente a construção de homens brancos, heterossexuais e cristãos, alijados a um paradigma eurocêntrico, interpelados por uma lógica de dominação e sujeição. Portanto, é de grande relevância colocar as lentes de gênero para observar e compreender os mecanismos de força que constituem o bullying escolar.

O interesse por esse estudo é uma tentativa de apreensão do fenômeno a partir de uma perspectiva gendrada e interseccional, questionando algumas produções acadêmicas nacionais que articulam os estudos sobre bullying escolar e gênero, na sua maioria, ainda com uma lógica dicotômica do sexo biológico. Tais reflexões fomentam a necessidade de pensarmos estratégias de resistência e luta no combate a esse tipo de violência uma vez que a saúde mental dos (as) envolvidos (as) está em constante risco, marginalizada e adoecida. 
Estudos sobre bullying escolar e sua relação com os gêneros: um binarismo que a ciência moderna insiste em manter

Alguns estudos abordam o bullying escolar e a sua relação com o gênero revelando que os meninos têm ocupado com mais frequência o papel de agressores, isto é, aqueles que agridem outras pessoas com o objetivo de machucar, prejudicar ou humilhar, fazendo valer a sua unidade de força. É importante ressaltar que a educação formal, a princípio, foi pensada apenas para os homens, fruto de um sistema político que os permitia transitar entre as esferas pública e privada com maiores liberdades sociopolíticas, e às meninas era permitido uma educação doméstica, obedecendo à lógica essencialista da docilidade, passividade e da maternidade (ZANELLO, 2018). Nesse sentido, é possível compreender os maiores envolvimentos dos meninos nos eventos de bullying escolar, principalmente no que tange o lugar de agressores. Mesmo que essa socialização comece na família, onde a mesma é, ao mesmo tempo, o seu espelho e a conexão com a sociedade, o ambiente escolar, historicamente, sempre atuou como aparelhagem ideológica, no controle de comportamentos e na regulação sobre as masculinidade e feminilidades.

A hegemonia do sistema patriarcal potencializou um tipo de masculinidade (heterossexual, branca, eurocêntrica, falocêntrica e cristã), estruturando as relações de poder em todas as esferas a partir da díade dominação/homens e subordinação/mulheres. Apesar dos avanços e das conquistas das mulheres, principalmente as feministas, ainda hoje é perceptível como essas questões estão na base social, revelando atitudes e mecanismos que legitimam esse sistema (MILLETT, 1975). Segundo os estudos de Claudio Hutz (2012), os meninos se identificam mais enquanto agressores, o que corresponde a $18 \%$, e a meninas se identificam mais enquanto vítimas, com o percentual de $25,9 \%$. Comumente, os meninos se utilizam dos meios físicos e verbais para coagirem a vítima, numa lógica de repetição e insistência a partir de uma suposta superioridade de gênero. Seria incoerente pensar que meninas estariam muito mais na posição de agressoras se pensarmos que a elas não foi autorizado o acesso ao poder, a educação para a política e para a guerra.

Certamente que existem muitas estudantes que estão envolvidas em episódios de bullying, isso não é um causa unilateral para explicar o maior envolvimento dos meninos, entretanto, esse fenômeno é reflexo de uma estrutura social e suas construções históricas, entretanto, isso não é uma tentativa de equilibrar as atitudes de violência causadas; é mais 
uma maneira de entender que o poder e as relações de força têm sido disputados com muito mais eminência entre os machos.

Além disso, ao consultar sobre produções acadêmicas realizadas (DE OLIVEIRAMINEGOTTO; PASINI; LEVANDOWSKI, 2013; FONSECA et al., 2012; BANDEIRA; HUTZ, 2012; ESTEVE; ARRUDA, 2014; CALBO et al.,2009), percebe-se que o conceito de gênero está diretamente relacionado com uma visão binária do sexo e essa questão revela algumas problematizações e lacunas epistemológicas, possivelmente. Ao pensar o gênero enquanto matriz identitária é preciso incluir as diversas formas de ser menino e menina, ou não ser, inclusive. Em pesquisas que envolvem a violência escolar, alguns (as) autores (as) que se debruçam sobre a relação do bullying e o gênero têm embasado o seu percurso teóricometodológico utilizando apenas as categorias menino e menina para fundamentar as suas análises, sem discutir as especificidades e os motivos que causam a prática desse violência nas escolas.

Analisar o bullying escolar sob a perspectiva dos (as) agressores (as), vítimas, vítimas/agressores (as), testemunhas e direcionar as causas a partir de categorias isoladas como apelidos, insultos, deboches, fofocas, ameaças, empurrões, chutes, socos, isolamentos, roubos de materiais, entre outras, não contempla as diversas tramas sociais e institucionais que impactam na saúde mental das pessoas envolvidas. É importante discutir sobre as especificidades desses comportamentos, que tipos de insultos, deboches e ameaças são essas, que oprimem e ditam a forma como os corpos devem se comportar. Apesar de suas importantes contribuições, as pesquisas revelam uma ausência de debates e discussões sobre os marcadores identitários que constituem a população dos estudantes, a citar, raça, sexualidade e gênero, pois o bullying, segundo Cléo Fantes (2005), começa pela não aceitação da diferença.

São insipientes os estudos que articulam diretamente a relação e incidência do bullying escolar com estudantes que não se enxergam dentro dos modelos de gênero e sexualidade vigentes, pois é nesta diferença que a violência se constitui e insiste. Se as meninas, por exemplo, são educadas a cumprirem um papel de gênero que está relacionado com uma noção naturalizada e de subordinação, isto é, docilizada, passiva, românica, sensível e frágil, o que acontece com as estudantes que jogam futebol ou se vestem fora dos padrões exigidos pela sociedade nos recreios escolares? Uma menina trans é reconhecida enquanto menina entre seus pares, entre a equipe pedagógica? Quantos estudantes LGBT são expulsos das escolas pelas relações nocivas e violentas que o preconceito provoca? Os problemas enfrentados pelos 
(as) estudantes negros (as) são o mesmo de estudantes brancos (as) no ambiente escolar? Quem deles (as) é atravessado (a) pelos efeitos do isolamento e a exclusão do racismo institucional?

Todas essas questões corroboram para pensarmos o bullying escolar para além de uma visão dicotômica e binária, que não contempla as diversas identidades, masculinidades e feminilidades, pois tal fenômeno é resultado também de sistemas de opressão que se intercruzam simultaneamente. Analisá-lo apenas com uma lógica percentual, com metodologias proeminentemente quantitativas que apontam, no conjunto de meninos e meninas, quem são os (as) agressores (as), vítimas e testemunhas, pode provocar o processo de invisibilização dessas outras e históricas opressões nos ambientes escolares.

Guacira Louro (2016) explicita que o contexto escolar, visto como um espaço de formação pedagógica e social, assume grande relevância para a compreensão das identidades de gênero e o lugar dos (as) alunos (as) nesse processo. Na escola, as pessoas são ensinadas, disciplinadas, medidas, avaliadas, examinadas, aprovadas, reprovadas, categorizadas, coagidas, consentidas, desenvolvidas e, acima de tudo, civilizadas; e diante dessa temática, eu questiono: o que é ser mesmo um menino ou uma menina, masculino ou feminino nesses espaços? Como o bullying pode ser resultado desse processo de enquadramento violento no exercício da pedagogia? Se o processo formativo do (a) aluno (a) abarca a dimensão ética, civil e moral, por que há uma resistência em admitir a diversidade de opiniões, de ideologias e formas de ser dos (as) sujeitos (as) (BUTLER, 2016)?

Operar com o sistema de investigação que se fundamenta no binarismo menino $\mathrm{x}$ menina para propor políticas públicas de combate ao bullying escolar invisibiliza e não produz agenciamento dos outros corpos. É importante especificar quais os motivos que levam ao comportamento insistente e violento entre estudantes, uma vez que somos um dos países que mais mata a população LGBT e jovens negros no mundo (CARDOSO; FERRO, 2012). Problematizar a maneira como a categoria gênero tem sido interpelada pelos estudos e pesquisas sobre bullying escolar é um convite a pensarmos como algumas identidades de gênero, que estão à margem das normas historicamente estabelecidas, são percebidas nesses contextos.

O bullying escolar e os sistemas de opressão históricos: como o conceito de interseccionalidade pode contribuir? 
O bullying escolar tem se tornado objeto de estudo de alguns (as) pesquisadores (as), pois o fenômeno é resultado de uma violência que envolve todos aqueles que estão no contexto educacional. Muitas pesquisas discutem o bullying a partir de matrizes e olhares distintos, mas que acabam se debruçando sob os aspectos visíveis desse processo. Em contrapartida, é importante pensar, no contexto brasileiro, como o bullying escolar pode ser reflexo de um processo de violências históricas dentro de um sistema de dominação e sujeição das minorias sociais, marginalizadas cotidianamente nas suas inúmeras formas.

Evidentemente, a violência escolar não é uma temática nova, no entanto, o bullying está no panorama das visibilidades e de produções acadêmicas que nos atentam para olharmos o fenômeno com uma demanda de urgência e prioridade, um desafio tanto das instituições de ensino como da Saúde Pública. Dessa maneira, torna-se importante articular quais são os sistemas de opressão que atuam para a manutenção do bullying escolar no Brasil, entendendo toda a sua construção histórica atrelada a diversos marcadores oriundos de um processo colonizador que se mantém até hoje, principalmente na educação formal.

Nesta perspectiva, perceber que eixos de dominação são esses, que atravessam a vida dos (as) estudantes envolvidos (as) e como isso pode ser associado, no cotidiano escolar, a questões que estruturam o modus operandi como a sociedade brasileira dinamiza as ideologias de exclusão é uma possibilidade a pensar o bullying escolar de um lugar diferente do que tem sido proposto.

Acredito que o conceito de interseccionalidade (CRENSHAW, 2002) nos possibilita empreender análises conceituais que denunciem a dinâmica opressora e suas relações com outras categorias, como raça, classe, gênero, colonialidade e heterossexualidade compulsória para entendermos como o bullying aparece no bojo desses mecanismos de interação e violência estruturantes. É importante pensar que esse conceito nos proporciona resgatar alguns marcadores identitários que podem ser invisibilizados se percebemos o bullying escolar enquanto fenômeno social novo e específico sem outras estruturas de dominação e de poder que o sustenta.

Vivemos em um país que produz e alimenta constantemente o racismo institucional, mesmo sob a pena jurídica de sua criminalização, como também ocupante dos primeiros lugares no índice de homicídios à população LGBT e feminicídio no mundo, e isso nos convoca a problematizar essas pautas a partir de uma matriz interseccional. Portanto, o bullying escolar também é um processo resultante do intercruzamento de todos esses dispositivos de violência e opressão (CARDOSO; FERRO, 2012). 
Kimberle Crenshaw é uma advogada norte-americana, negra, teórica e feminista que tem construído suas produções acadêmicas com foco nas dinâmicas da raça e gênero, abordando a urgência de um olhar interseccional para analisar essas relações de opressão que as mulheres têm vivido ao longo da história humana. Ela vai elaborar, através do documento para o Encontro de especialistas em aspectos da discriminação racial relativos ao gênero (2002), pensamentos e análises que criticam alguns posicionamentos que estruturam a Declaração Universal de Direitos Humanos e tece críticas aos modelos de políticas públicas construídos para tratar as temáticas de gênero na sociedade. Segundo Kimberle Crenshaw (2002), os documentos produzidos com o objetivo de proteger as mulheres se tornam incipientes uma vez que a categoria gênero, aportado na sua perspectiva universalizante sobre a mulher, acaba por invisibilizar a vivência e sofrimento de outros grupos de mulheres que não são contemplados dentro das suas produções étnicas e identitárias. Com isso, a autora propõe um olhar sobre a interseccionalidade enquanto categoria analítica, enquanto um conceito que vai possibilitar entender como a associação de sistemas múltiplos de subordinação tem sido descritos na vida das mulheres racializadas. Em suma, a interseccionalidade,

[...] é uma conceituação do problema que busca capturar as consequências estruturais e dinâmicas da interação entre dois ou mais eixos da subordinação. Ela trata especificamente da forma pela qual o racismo, o patriarcalismo, a opressão de classe e outros sistemas discriminatórios criam desigualdades básicas que estruturam as posições relativas de mulheres, raças, etnias, classes e outras (CRENSHAW, 2002, p. 177).

É importante refletir que a depender do contexto histórico e da sua geopolítica, esses eixos de dominação e subordinação acontecem de forma distintas. Então, se por um lado as mulheres anglofônicas enfrentam uma ordem de gênero patriarcal onde a categoria raça não é tão relevante, por outro lado, as mulheres da latinoamérica terão os seus espaços cerceados e sua força política esquadrinhada pela mesma categoria. Isto é, articular o conceito de interseccionalidade implica na problematização de que mulheres e homens sofrem de maneiras diferentes em relação aos processos de exclusão e subordinação sociais. Os estudos sobre interseccionalidades e a sua relação com raça e gênero vão alargar os processos analíticos da teoria feminista, ampliando o olhar sobre as diversas mulheres e como os sistemas de opressão (racismo e o sexismo) atravessam a realidade desses corpos.

Sendo assim, perceber a interseccionalidade enquanto categoria propicia um entendimento mais político de como essas matrizes de opressão se articulam, resultando na 
violação das identidades das mulheres negras como também de homens em situação de exclusão social. Nesse panorama, é de grande valia investigar e analisar o bullying escolar a partir de um olhar interseccional, porque os atos de violência que caracterizam o espaço edueacional não acontecem da mesma forma com estudantes negros (as), gays, bissexuais, não binários (as), lésbicas, transexuais e transgêneros (as), entre outras identidades. Se compreendermos essas dinâmicas, perceberemos que o bullying incide de maneira avassaladora sobre esses corpos.

Esse fenômeno social e dito contemporâneo (DE OLIVEIRA-MINEGOTTO; PASINI; LEVANDOWSKI, 2013) traz eixos de dominação históricos, de séculos e percebê-lo em sua especificidade invisibiliza a realidade e sofrimento de muitos (as) sujeitos (as).

No Brasil, pensando no racismo institucional e na LGBTfobia enquanto práticas de massacre frequente, torna-se fundamental construir esse olhar sobre esse fenômeno como um processo complexo oriundo também dessas matrizes opressoras. Portanto, o bullying escolar, por si só, não dá conta desses eixos que se articulam dentro das salas de aula e dos corredores das escolas se pensarmos que milhares de estudantes são excluídos (as) e violentados (as) por não estarem dentro de um padrão social estabelecido.

\section{Bullying escolar e o racismo no Brasil: fenômeno atual, violência antiga}

As dinâmicas do racismo estão por toda parte e nas instituições de ensino não poderia ser diferente. A natureza velada e a falta de políticas públicas de combate ao racismo se tornam cada vez maiores mesmo com o atravessamento da tecnologia na sociedade e liberdade de mobilização no enfrentamento dessa estrutura. $\mathrm{O}$ advento do bullying convocou a comunidade acadêmica a se debruçar sobre os seus impactos e consequências na saúde mental dos (as) estudantes por entenderem a gravidade dos danos causados. Mas até que ponto tratar todos os tipos de violência escolar enquanto bullying proporcionam grandes avanços? Com a criminalização do racismo, seria mais fácil para as instituições de ensino lidar com essa generalização em prol do não enfrentamento desse problema? É importante pensar nessas tessituras e possibilidades de invisibilização, pois o racismo assumiu ao longo da história uma forma muito peculiar no tratamento e na estruturação das hierarquias sociais no Brasil, assim como na manutenção dos privilégios de um grupo (racial) em detrimento de outro (BERNARDO; MACIEL, 2015). 
Por um lado, a urgência de medidas socioeducacionais se apresenta com extrema relevância no combate ao bullying escolar, por outro, o enfrentamento do racismo dissociado desse fenômeno o invisibiliza e silencia milhares de vozes em sofrimento. Sabe-se que ainda existe uma ideologia discursiva da hierarquização natural das raças humanas e que a produção de crenças que legitimam essas práticas está cada vez mais explícita, nos fazendo perceber o quanto isso precisa ser enfrentado e denunciado.

\begin{abstract}
Racismo, em primeiro lugar, é referido como sendo uma doutrina, quer se queira científica, quer não, que prega a existência de raças humanas com diferentes qualidades e habilidades, ordenadas de tal modo que as raças formem um gradiente hierárquico de qualidades morais, psicológicas, físicas e intelectuais. [...] além de doutrina, o racismo é também referido como sendo um corpo de atitudes, preferências e gostos instruídos pela ideia de raça e superioridade racial, seja no plano moral, estético, físico ou intelectual ( GUIMARÃES, 2004, p. 17).
\end{abstract}

A institucionalização do racismo e o seu emaranhamento na política, na educação, nos espaços públicos de poder formal e informal, na ciência, na mídia, entre outras esferas, é resultante de uma ideologia da branquitude. O mito da democracia racial, enraizado no pensamento do povo brasileiro desde o seu processo de socialização primária, é uma tentativa de silenciamento do nosso passado e da nossa história, observando o regime escravocrata brasileiro. O estupro colonial, como elucida Sueli Carneiro (1995), acometido às mulheres negras em condição de escravas, tem sofrido tentativas seculares de apagamentos na construção identitária do Brasil. Essa estratégia de aniquilação histórica do nosso povo aparece nos livros didáticos, na forma como o conhecimento é repassado nas instituições educacionais, estimulado pelo paradigma eurocêntrico e, compulsoriamente, atestando um viés de sucesso de vida a partir do branqueamento, o que é "[...] frequentemente considerado como um problema do negro que, descontente e desconfortável com sua condição de negro, procura identificar-se como branco, miscigenar-se com ele para diluir suas características raciais" (BENTO, 2002, p.1).

Heróis brancos, princesas brancas, vilões e/ou monstros com vestes pretas, o "bicho da cara preta". A dualidade permanece presente para demarcar o bem e o mau, o certo e o errado, o humano e o animal, mobilizando e controlando as formas de produção intelectual dos cidadãos para a convivência em sociedade. Mesmo com a implementação da Lei 10.639/032²

\footnotetext{
${ }^{2}$ Altera a Lei no 9.394, de 20 de dezembro de 1996, que estabelece as diretrizes e bases da educação nacional, para incluir no currículo oficial da Rede de Ensino a obrigatoriedade da temática "História e Cultura AfroBrasileira", e dá outras providências.
} 
o racismo ainda é alimentado nas escolas, muitas vezes mascarado e que insiste, nos campos discursivos, em ser confundido entre as diferentes formas de discriminação, generalizando-as como bullying. O cotidiano escolar, ao não possibilitar a construção da autoestima, da negritude e do conhecimento da história das populações afro-brasileiras, reforça a violência constante do racismo, contribuindo para a invisibilidade do (a) negro (a) para si próprio e para o (a) outro (a).

É nessa reflexão que o olhar interseccional nos possibilita produzir narrativas plurais sobre o fenômeno do bullying escolar sem descaracterizar a natureza de sistemas opressores como o racismo, que se multifaceta nas práticas cotidianas através de comportamentos ditos irrelevantes, brincadeiras de criança, mas que degradam diariamente a saúde mental da população negra. Segundo Maria Aparecida Bento (2002, p.5), é nesta perspectiva que se instaura uma "[...] relação dialógica: por um lado, a estigmatização de um grupo como perdedor, e a omissão diante da violência que o atinge; por outro lado, um silêncio suspeito em torno do grupo que pratica a violência racial e dela se beneficia, concreta ou simbolicamente". A construção da identidade nacional do Brasil é atravessada por contribuições civilizatórias de diversos grupos étnico-raciais. A nossa cultura se funda a partir de matrizes culturais variadas, principalmente africanas e suas diásporas, presentes na arte, na arquitetura, na culinária, na religião, nas relações sociais e nos nossos corpos (ALVES; DE JESUS; SCHOLZ, 2015).

E mesmo com todos esses marcadores, o racismo institucional invisibiliza tais contribuições. Então, se as instituições de ensino são uma extensão do Estado, e esse Estado é constituído pelas estruturas políticas de dominação, a escola é um espaço reprodutor das diversas opressões historicamente construídas. O que se percebeu, desde o início, como bem aponta Guacira Louro (2016, p.7), é que "[...] os propósitos desses investimentos escolares eram a produção de um homem e de uma mulher 'civilizados', capazes de viver em coerência e adequação na sociedade brasileira". Mas a população negra nunca esteve presente e nunca foi incluída quando se pensava em uma política educacional para cidadãs e cidadãos, pois o civilizado sempre teve como referência o homem branco, europeu, heterossexual e cristão; aos negros e negras não cabiam à faculdade intelectual e de processamento da razão, pois o "embranquecimento" estava articulado, primeiramente, com a doutrina da superioridade branca. 
Se as dinâmicas do racismo institucional continuam vigentes, dos gestos sutis aos mais explícitos, como se estrutura a saúde mental dos (as) estudantes negros (as) que sofrem bullying cotidianamente? Podemos ter duas opressões distintas, mas que se intercruzam neste aspecto: primeiramente, a racial que, como vimos, é silenciada e legitimada pela força da eugenia, presente nas relações históricasde poder e de dominação, através dos discursos racistas e de ódio praticados nas escolas; segundo, o bullying, que de certo modo permite que o racismo seja invisibilizado e generalizado a uma espécie de brincadeira de mau gosto entre crianças e adolescentes. Nesse aspecto o racismo perde, portanto, com o advento do bullying, o seu caráter criminal.

Sentir-se não pertecente, discriminado (a) e exotificado (a) dentro de um espaço que se fomenta valores éticos e morais com base no respeito às diferenças, autonomia e a construção coletiva é uma violência sem precedentes. Entender que o processo de evasão é muito mais que uma questão estrutural, de localização geográfica, de espaço físico, de conteúdo programático e relatórios com indicadores visíveis é um passo essencial para compreendermos a natureza perversa do racismo nas escolas. O enfrentamento do racismo é de responsabilidade de todos (as), é uma questão de saúde pública.

\footnotetext{
O desafio que está posto para a saúde coletiva é o de inaugurar um novo processo de escuta e reconhecimento dos diferentes valores e práticas civilizatórias que constituem a sociedade brasileira. Rompendo, assim, com o olhar preconceituoso e racista que ainda hoje é lançado às pessoas de ascendência africana, bem como com a perspectiva de desagência e de humanidade de concessão e subalterna até então levados a efeito nas relações étnico-raciais de nosso país (ALVES; DE JESUS; SCHOLZ, 2015, p. 878).
}

As análises e pesquisas que estabelecem um recorte racial interconectando o bullying às formas de violência racial no contexto escolar são muito incipientes. A produção de pesquisas em psicologia, principalmente, que se debruçam sobre os aspectos da saúde mental e o processo de aprendizagem de estudantes negros (as) que sofrem racismo nas escolas pode ajudar na elaboração de políticas públicas e estratégias de enfrentamento dessa mazela. Assim, compreender o bullying escolar enquanto um fenômeno social atual sem localizar onde ele acontece e quais sistemas de opressão estão presentes nesta dinâmica é um risco, porque ele pode ser mais um subterfúgio para a sociedade camuflar a ideia de raça e do racismo nas escolas e, como afirma Teresinha Bernardo e Regimeire Maciel (2015, pp. 198), “[...] o bullying permite uma tolerância maior por parte de educadores e gestores. Isso talvez 
esteja relacionado com a generalização que o termo assumiu: é tudo e não é nada ao mesmo tempo".

Bullying escolar, sexualidades e identidades de gênero: um olhar para além das masculinidades e feminilidades hegemônicas

O panorama das estatísticas realizadas pelas pesquisas que adotam o eixo analítico para investigar a relação do bullying escolar com o gênero e sexualidade merece um aprofundamento e talvez maior criticidade. Apontar dados estatísticos entre os pares, utilizando um olhar apenas descritivo de atitudes comportamentais ditos de meninos e meninas a partir de uma tríade agressores (as), vítimas e vítima/agressor, sem uma perspectiva sócio-histórica, revela a necessidade de repensarmos sobre outras práticas referentes ao fenômeno bullying e suas implicações. Pensar no gênero enquanto categoria de análise (SCOTT, 1995) nos convoca a entender as masculinidades e feminilidades historicamente construídas, propondo uma crítica ao binarismo e incluindo as múltiplas identidades de gênero existentes (BUTLER, 2003).

O bullying escolar articulado ao gênero não pode se ater ao mundo de meninos e meninas, uma vez que falar sobre esse processo é uma possibilidade a olharmos para os (as) estudantes que não se enxergam nesse lugar, que não compartilham desse modelo heterossexual socialmente estabelecido, sofrendo os atravessamentos da marginalização e sofrimento. Para isso, é importante iniciar esta sessão trazendo outros dados relevantes a fim de interpelar outros marcadores para os estudos sobre gênero e sexualidade.

Segundo o Grupo Gay da Bahia, a cada 19 horas um LGBT morre de forma violenta vítima de LGBTfobia no Brasil, o que coloca o país como campeão mundial em crimes contra minorias sexuais. Se os estudos sobre bullying escolar são na maioria das vezes relatados como um fenômeno atual e que demanda um olhar mais atento da Saúde Pública, é preciso contextualizar as interfaces e estruturas que dinamizam a nossa sociedade e faz do Brasil ser o campeão em “crimes de ódio" (MOTT; MICHELS, 2019). Ainda sobre isso, o Grupo Gay da Bahia, em relatório produzido, anuncia que

420 LGBT+ (lésbicas, gays, bissexuais e transexuais) morreram no Brasil em 2018 vítimas da homolesbotransfobia: 320 homicídios (76\%) e 100 suicídios (24\%). Uma pequena redução de $6 \%$ em relação a 2017, quando registraram-se 445 mortes, numero recorde nos 39 anos desde que o Grupo Gay da Bahia iniciou esse banco de dados (MOTT; MICHELS, 2019, p.4). 
Pensar esses homicídios enquanto resultado da punição e negação das identidades de gênero e sexualidades ditas abjetas, caracterizados pela intolerância e repulsa ao diferente, propõe uma reflexão sobre os modelos educacionais os quais as escolas vêm construindo. Se os países latino-americanos ancoram os maiores índices de homofobia do ocidente, incluindo o Brasil, como compreender o bullying escolar sem os intercruzamentos desses sistemas de opressão? São essas convocações que apontam para uma análise mais crítica e substancial desse fenômeno (CASTAÑEDA, 1990 apud NASCIMENTO, 2010).

A princípio, o que se pode constatar é a escola enquanto espaço de inúmeras práticas sexistas, em que discursos são fortemente reproduzidos sobre os lugares de homens e mulheres na sociedade. Em pleno século XXI, percebemos o quanto a educação formal pode contribuir para que as construções identitárias saiam dessas representações hierarquizadas e reprodutoras, de que devem existir certos modelos e lugares para homens e outros para mulheres, sem considerar a diversidade que existe nas relações humanas, pois identidades de gênero não devem ser pautadas como inferiores ou superiores.

Se o bullying é percebido como atitudes de violência escolar que acontecem com a intenção de humilhar, agredir, excluir e isolar, de maneira repetitiva, rotineira, como forma de imposição do poder de um determinado grupo sob o outro, é muito provável que as vítimas dessas agressões sejam estudantes com características físicas, socioeconômicas, de etnia e orientação sexual, específicas (SMITH, 2002).

A intolerância ao diferente tem ganhado força nas escolas em nível mundial, imprimindo um modelo de civilização questionável e opressor nas relações entre a equipe pedagógica e os (as) alunos (as), gerando sofrimento e afetando diretamente o processo de ensino-aprendizagem dos (as) envolvidos (as). Refletir sobre a importância de se combater o bullying escolar sem articular essas questões potencializa um caráter generalizador de violências históricas como homofobia, racismo, transfobia, lesbofobia, misoginia, entre outras, pois, como elucida Berenice Bento (2011, p. 558), “[...] a natureza da violência que leva uma criança a deixar de frequentar a escola porque tem que trabalhar para ajudar a família não é da mesma ordem daquela que não consegue se concentrar nos conteúdos transmitidos porque é 'diferente'".

Segundo os indicadores do SUS, no período de 1980 a 2005, foram assassinados 2.511 homossexuais no Brasil, sendo que a maior parte dos crimes ocorreu por motivos homofóbicos. De acordo com os relatos obtidos nessa pesquisa, a maioria das violências ocorreu com o envolvimento de pessoas desconhecidas, totalizando $48 \%$ dos casos. Os agressores relacionados com o cotidiano das vítimas estão 
concentrados nos familiares (12\%), em segundo lugar, citam colegas de escolafaculdade, sendo a terceira maior pontuação referente a amigos conhecidos (9\%); os demais agressores totalizaram 12\% (CARDOSO; FERRO, 2012, p. 555).

O modelo hegemônico posto para uma parcela pequena da sociedade, aqui entendido como heterossexual, branco, católico-cristão e masculino, estabelece as relações do (a) sujeito (a) com o mundo, a forma como este (a) deve se comportar e como os seus papeis sociais devem ser exercidos. O contexto escolar, visto como um espaço de formação pedagógica e social, assume uma relevância para a compreensão das identidades de gênero, das sexualidades e o lugar do processo formativo do (a) aluno (a) nesse contexto. Na escola, as pessoas são ensinadas, disciplinadas, medidas, avaliadas, examinadas, aprovadas, categorizadas, coagidas, consentidas, desenvolvidas e, acima de tudo, civilizadas, e o corpo, nos espaços educacionais, é sinônimo de perícia e constante punição daquilo que não está na concepção do "civilizado" (FOUCAULT, 2005).

Ao versar sobre os modelos educacionais da atualidade, quantas crianças e jovens são impedidas de construírem a sua autonomia e exercerem as suas identidades livremente? Como os estudos sobre gênero e sexualidade podem propor novos olhares para o fenômeno do bullying escolar? Dados que apontem para um quadro geral de meninos e meninas, descrevendo os possíveis motivos sem problematiza-los trarão que tipo de ações e estratégias significativas?

De início, é importante discutir sobre que processo de civilização é esse, que diz qual padrão comportamental é visto como normal e aceito pelas instituições de ensino, e como o bullying tem sido debatido no contexto da Saúde Pública. Até os dias atuais, a escola está voltada para a "adequação" do (a) aluno (a) em sociedade e as ações pedagógicas não têm contemplado debates sobre diversidade e diferença em sua complexidade, se atendo às páginas dos planejamentos e de relatórios educacionais com o objetivo de descrever, no processo de ensino, a qualificação do que é "civilizado".

Um exemplo prototípico da falta de incentivo de discussões e ações de enfrentamento para a promoção desses debates foi a retirada dos termos "identidades de gênero" e “orientação sexual” da Base Nacional Comum Curricular, na sua versão final lançada em dezembro de 2017. O Ministério da Educação $^{3}$ ordenou que o Conselho Nacional de

\footnotetext{
${ }^{3}$ O Ministério da Educação, órgão da administração federal direta, tem como área de competência a política nacional de educação; a educação infantil; a educação em geral, compreendendo ensino fundamental, ensino médio, educação superior, educação de jovens e adultos, educação profissional e tecnológica, educação especial e educação a distância, exceto ensino militar; a avaliação, a informação e a pesquisa educacionais; a pesquisa e a
} 
Educação retirasse essas temáticas e isso, mais uma vez, revela as contradições de uma realidade perversa e repleta de interesses políticos. Sendo assim, como combater o bullying escolar com esses recortes se os órgãos públicos negligenciam a importância desses debates para o enfrentamento dessas violências? O que se percebe, desde o início, é que o Estado não trabalha diretamente no enfrentamento dessas temáticas, abrindo espaço para a persistência desse tipo de violência. A lógica de enquadramento e controle dos corpos parece sobreviver sem nenhum tipo de impeditivo.

Diariamente, crianças e adolescentes sofrem pelas relações desiguais de poder e coerção de grupos hegemônicos que se utilizam das brincadeiras para oprimir as minorias. Nesse jogo violento e de manutenção desses comportamentos, os (as) agressores (as) constroem uma lógica de dominação fazendo valer as suas unidades de força, muitas vezes apoiados pelos professores (as), família e equipe pedagógica, justificando como natural para o desenvolvimento desses (as) estudantes. Mas até que ponto o bullying escolar nos aproxima dessas realidades? Quais estratégias de intervenção e de análise são necessárias para denunciar essas práticas sem descaracterizá-las das suas construções políticas e históricas? Nessa perspectiva, apesar de tantos estudos, o bullying se aproxima do conceito de preconceito, principalmente quando refletimos sobre os fatores sociais que determinam os grupos-alvo, e sobre os indicativos da função psíquica para aqueles (as) considerados (as) agressores (as). Essa proximidade, de acordo com Deborah Antunes e António Zuin (2008), leva à hipótese de que o que atualmente tem sido denominado bullying escolar é um fenômeno há muito conhecido pela humanidade, mas que ganhou nova terminologia pela ciência moderna que se ilude ao tentar controlá-lo via classificação e aconselhamentos.

\section{O bullying escolar e suas implicações na saúde mental}

A Organização Mundial da Saúde (1946) conceitua saúde como "estado de completo bem estar físico, mental e social, e não somente a ausência de enfermidade ou invalidez". Essa afirmativa nos dá a possibilidade de situar a gravidade e a emergência de políticas públicas e de saúde para o amparo dos (as) estudantes que estão envolvidos (as) no bullying escolar, pois a saúde é um conceito que envolve o bem estar biopsicoespiritual das pessoas, sendo legitimada como um direito constitucional e que está para além da ausência de

extensão universitárias; o magistério e a assistência financeira a famílias carentes para a escolarização de seus filhos ou dependentes (BRASIL, 2014). 
enfermidades. Pensar que a violência se manifesta de inúmeras formas, atuando de maneira sutil, velada e/ou explícita sob a lógica dos sistemas de opressão racista, sexista, machista, homofóbico, lesbofóbico e transfóbico, que estruturam a sociedade, pode ser um risco à integridade dos (as) estudantes se tivermos uma noção unidimensional do que seja violência. A intimidação e a vitimização são dinâmicas complexas que se produzem nas relações sociais, principalmente nas escolas, e enquanto profissionais da educação não podemos compreender esse processo atribuindo a violência apenas à vítima, uma vez que estudos apontam que tal fenômeno é um desmembramento das relações familiares caracterizadas frequentemente como contextos hostis e também reprodutores de padrões sociais estabelecidos (DE OLIVEIRAMINEGOTTO; PASINI; LEVANDOWSKI, 2013; FONSECA et al.,2012; BANDEIRA; HUTZ, 2012).

O bullying escolar resulta em severas repercussões a médio e longo prazo para agressores (as) e vítimas, impactando na aprendizagem, na autoestima, no isolamento, podendo ocasionar, no seu aspecto mais grave, episódios de depressão e suicídio. Nesse processo complexo e doloroso, estudantes se negam a voltar para a escola depois de episódios constantes de humilhação, exclusão e agressão a que são expostos (as). A necessidade de um olhar mais sensível para essa prática precisa ser pensada com urgência, compreendendo os impactos dessa violência na saúde mental e física desses (as) jovens. Por outro lado, é preciso entender a nossa história, a forma como as identidades foram concebidas, privilegiadas e marginalizadas, porque existem motivações subjetivas por parte dos (as) agressores (as) que orientam as suas ações discriminatórias. De acordo com Maria Fonseca et al. (2012), essas motivações veiculam estereótipos e hierarquias sociais que precisam ser desvendados e compreendidos para o enfrentamento das tensões e dos conflitos nas escolas, investigando as dinâmicas de poder e os privilégios que determinados corpos possuem em detrimento de outros.

Refletir qual o perfil de estudante se torna o maior alvo do bullying escolar nos convida a questionar esse fenômeno visto como algo atual, associando-o a outros sistemas de exclusão sociais que não cessam, apesar dos movimentos de fissura e de rompimento dessas estruturas. Sabemos que cada pessoa elabora as suas construções internas e a sua relação com o mundo de maneira idiossincrática, por isso é fundamental analisar como essa violência atravessa cada estudante sem deixar de perceber como os marcadores identitários operam nos seus corpos, e como o Estado e a escola entendem a dimensão da saúde mental e o processo de adoecimento dessas pessoas. Restringir o (a) sujeito (a) ao campo do civilizado, atrelado 
(a) ao binarismo sexual sem considerar e perceber a dimensão das múltiplas identidades existentes que se expressam no cotidiano da vida e, portanto, escolar, resultam em dificuldades de um ensino pautado na produção social da identidade e da diferença, onde questões do multiculturalismo e da diferença tornaram-se eixos centrais na teoria educacional crítica e até mesmo nas pedagogias oficiais. E sobre essa questão, da intolerância ao diferente, da tentativa de apagamento do outro que podemos ver os danos morais, psicológicos e físicos causados (DA SILVA, 2012).

Se a educação formal está pautada nos princípios da Constituição Federal (1988), caracterizado pelo direito à vida, ao direito de ir e vir, a liberdade de escolha seja ela através da orientação sexual, da religião, entre outras, com base no respeito e cidadania, o que aconteceu com a escola? No que a educação tem se transformado? Quais são os impactos causados na saúde dos (as) jovens envolvidos (as) no bullying? Por um lado, as vítimas sofrem uma deterioração da sua autoestima e do conceito que tem de si; por outro, os (as) agressores (as) também precisam de auxílio, visto que sofrem grave deterioração de sua escala de valores. Se o Brasil é o país que mais mata a população LGBT no mundo, precisamos alertar a Saúde Pública a pensar ações e estratégias de enfrentamento com um viés interseccional (CARDOSO; FERRO, 2012).

Discutir possibilidades de prevenção e enfrentamento do bullying escolar sugere a promoção de políticas educacionais voltadas para as equipes pedagógicas, principalmente os (as) professores (as) que parecem encontrar dificuldades ao lidarem com questões de identidades de gênero, sexualidades, racismo, homofobia, transfobia, lesbofobia e misoginia associados ao bullying, em sala de aula. A ausência de uma perspectiva socioexistencial pautada nas práticas cotidianas dos (as) sujeitos (as) estudantes, alijadas pelo pragmatismo tecnicista de conceber a formação, os (as) tornam despreparados (as), em sua maioria, para mediar essas relações. Analisar e mediar uma sala de aula implica em compreender a complexidade das relações de poder que emergem ali. Os seres humanos são o resultado do processo sócio-histórico e isso implica na compreensão de que a cultura atravessa esse contexto de maneira desenfreada e, muitas vezes, avassaladora, uma vez que a aprendizagem também se dá pela experiência.

Portanto, perceber os impactos causados pelo bullying escolar na vida de milhares de estudantes significa atentar-se para a saúde mental dos mesmos e lembrar-se constantemente das opressões historicamente construídas que violam os seus corpos até hoje. No Brasil, existe uma tendência a colocar o bullying escolar como um evento social atual desarticulado do 
paradigma cristão, branco, eurocêntrico, masculino e heterossexual, com descrições quantitativas, em sua maioria, carentes de uma abordagem plural. Se a escuta é o principal instrumento de acolhimento dessas vítimas e a escola não está preparada para mediar esses atravessamentos, a saúde mental dos (as) envolvidos (as) estará em constate risco.

\section{Considerações finais}

O bullying é um fenômeno social que nos alerta para as inúmeras dimensões da violência escolar. Ele carrega características e construções de uma sociedade contemporânea, mas é preciso situar o contexto onde isso acontece e quais processos são responsáveis pela sua dinâmica e mecanização nas diferentes culturas.

No Brasil, onde várias estruturas se articulam entre si, como o racismo, a LGBTfobia e a misoginia, lançar um olhar sobre qualquer tipo de violência sem essa proposta interseccional pode incidir na invisibilização dos sofrimentos psíquicos de jovens que são diariamente atravessados (as) por esses eixos de opressão. Por isso, a necessidade de mais produções na área da Psicologia, Sociologia e da Antropologia, uma vez que o caráter de muitos estudos realizados não contemplam as diversas vozes.

Se a escola tem responsabilidade na produção e desenvolvimento de novos cidadãos e cidadãs, trazendo no bojo dos seus planos pedagógicos a prioridade no combate às violências e o fomento da consciência e importância do respeito e da diferença, precisamos questionar qual o modelo de educação é viável para romper com as desigualdades e assimetrias de gênero, raça, orientação sexual e outros marcadores identitários. Compreender que o combate às diversas formas de violência escolar, assim como o bullying, requer vigilância e resistência em relação aos direitos e a promoção de políticas públicas com o objetivo de visibilizar os sofrimentos das vítimas envolvidas nesse processo.

O bullying escolar não pode se tornar uma espécie de matriz generalizadora das outras violências que já existem há séculos e assolam a sociedade brasileira. É fundamental a construção de ações e políticas de equidade para o enfrentamento desse tipo de violência, entretanto, o bullying não encerra todas as outras, pelo contrário, ele existe como resultado de opressões e violações históricas sobre os nossos corpos.

\section{Referências}

Vol. 02, N. 01, Jan. - Mar., 2019 · www.revistas.unilab.edu.br/index.php/rebeh 
ALVES, Míriam Cristiane; JESUS, Jayro Pereira de; SCHOLZ, Danielle. Paradigma da afrocentricidade e uma nova concepção de humanidade em saúde coletiva: reflexões sobre a relação entre saúde mental e racismo. Saúde debate, Rio de Janeiro, v. 39, n. 106, p. 869-880, set, 2015. Disponível em: < http://www.scielo.br/pdf/sdeb/v39n106/0103-1104-sdeb-39-10600869.pdf $>$. Acessado em 5 de fevereiro de 2019.

ANTUNES, Deborah Cristina; ZUIN, Antônio Álvaro Soares. Do bullying ao preconceito: os desafios da barbárie à educação. Psicologia \& Sociedade, 20 (1) 33-42, 2008. Disponível em: $<$ http://www.scielo.br/pdf/psoc/v20n1/a04v20n1.pdf $>$. Acessado em 8 de fevereiro de 2019.

BANDEIRA, Cláudia de Moraes; HUTZ, Claudio Simon. As implicações do bullying na auto-estima de adolescentes. Revista Semestral da Associação Brasileira de Psicologia Escolar e Educacional, São Paulo, Vol. 14, N. 1, pp. 131-138, Janeiro/Junho, 2010. Disponível em: < http://www.scielo.br/pdf/pee/v14n1/v14n1a14 >. Acessado em 8 de fevereiro de 2019.

BENTO, Berenice. Na escola se aprende que a diferença faz a diferença. Revista Estudos feministas, 2011, vol.19, n.2, pp.549-559. Disponível em: < http://www.scielo.br/pdf/ref/v19n2/v19n2a16.pdf >. Acessado em 30 de janeiro de 2019.

BENTO, Maria Aparecida Silva. Psicologia social do racismo. Petrópolis: Vozes, 2002.

BERNARDO, Teresinha; MACIEL, Regimeire Oliveira. Racismo e educação: um conflito constante. Contemporânea, São Paulo, v. 5, n. 1 p. 191-205, Jan.-Jun, 2015. Disponível em: < http://www.contemporanea.ufscar.br/index.php/contemporanea/article/view/302/134 >. Acessado em 11 de fevereiro de 2019.

BRASIL. Lei 13005, de 25 de junho de 2014. Aprova o Plano Nacional de Educação - PNE e dá outras providências. Brasília, DF., Diário Oficial da União. Brasília, DF, 26 jun. 2014. Disponível em: < http://www.planalto.gov.br/ccivil_03/_Ato2011-2014/2014/Lei/L13005.htm >. Acessado em 29 de janeiro de 2019.

BUTLER, Judith P. Problemas de gênero: feminismo e subversão da identidade. $11^{\mathrm{a}}$ ed.- Rio de Janeiro: Civilização Brasileira, 2016.

CALBO, Adriano Severo; BUSNELLO, Fernanda de Bastani; RIGOLI, Marcelo Montagner; SCHAEFER, Luiziana Souto; KRISTENSEN, Christian Haag. Bullying na escola: comportamento agressivo, vitimização e conduta pró-social entre pares. Contextos Clínicos, 2(2):73-80, julho-dezembro, 2009. Disponível em: < http://revistas.unisinos.br/index.php/contextosclinicos/article/view/4915 >. Acessado em 3 de fevereiro de 2019.

CARDOSO, Michele Rodrigues; FERRO, Luís Felipe. Saúde e População LGBT: Demandas e Especificidades em Questão. Psicologia: ciência e profissão, Paraná, 32(3), pp. 552-563, 2012. Disponível em: < http://www.scielo.br/pdf/pcp/v32n3/v32n3a03.pdf >. Acessado em 25 de janeiro de 2019.

CARNEIRO, Sueli. Gênero, raça e ascenção social. Rev. Estudos Feministas, Salvador, n. 2. v. 1, pp. 544-552, 1995. Disponível em: < https://www.geledes.org.br/wp- 
content/uploads/2015/05/G\%C3\%AAnero-ra\%C3\%A7a-e-ascen $\% \mathrm{C3} \% \mathrm{~A} 7 \% \mathrm{C} 3 \% \mathrm{~A} 3 \mathrm{o}$ social.pdf $>$. Acessado em 20 de janeiro de 2019.

CRENSHAW, Kimberlé. Documento para o encontro de especialistas em aspectos da discriminação racial relativos ao gênero. Rev. Estudos Feministas, Salvador, n.171 v. 1, 2002. Disponível em: < http://www.scielo.br/pdf/ref/v10n1/11636.pdf > . Acessado em 15 de janeiro de 2019.

DE OLIVEIRA-MENEGOTTO, Lisiane Machado; PASINI, Audri Inês; LEVANDOWSKI, Gabriel. O bullying escolar no Brasil: uma revisão de artigos científicos. Revista Psicologia: Teoria e Prática, São Paulo, 15(2), pp. 203-215, maio-ago, 2013. Disponível em: < http://pepsic.bvsalud.org/pdf/ptp/v15n2/16.pdf > . Acessado em 18 de janeiro de 2019.

DINIS, Nilson Fernandes. Educação, relações e diversidade sexual. Educação \& Sociedade, Campinas, vol. 29, n. 103, pp. 477-492, agosto, 2008. Disponível em: < http://www.scielo.br/pdf/es/v29n103/09.pdf >. Acessado em 10 de fevereiro de 2019.

ESTEVE, Crislaine Elza Aparecida; ARRUDA, Aparecida Luzivotto Medina Martins. Bullying: quando a brincadeira fica séria, causas e consequências. Revista Eletrônica Saberes da Educação, São Roque, Vol. 5, n. 1, pp. 1-36, 2014. Disponível em: < http://docs.uninove.br/arte/fac/publicacoes_pdf/educacao/v5_n1_2014/Crislaine.pdf >. Acessado em 8 de fevereiro de 2019.

FANTE, Cléo. Fenômeno Bullying: como prevenir a violência nas escolas e educar. Florianópolis, 19(2): 549-559, maio-agosto, 2011.

FONSECA, Maria Helena; FONSECA, Sarah Gonçalves; GOMES, Cecília Soares; NOGUEIRA, Débora Maysa Gomes; SOARES, Letícia Santos. Bullying: forma de violência e exclusão escolar. Revista Motricidade, Vila Real, vol. 8, n. Supl. 2, pp. 797-802, ago-set, 2012. Disponível em: < https://www.redalyc.org/pdf/2730/273023568100.pdf >. Acessado em 10 de fevereiro de 2019.

FOUCAULT, Michel. A história da sexualidade. São Paulo: Graal Editora, 2005.

GUIMARÃES, Antonio Sérgio Alfredo. Preconceito e discriminação. São Paulo, Fundação de Apoio à Universidade de São Paulo/Editora 34, 2004.

LOURO, Guacira Lopes. O corpo educado: Pedagogias da sexualidade. In: O corpo educado: pedagogias da sexualidade. $3^{a}$ edição. Belo Horizonte: Autêntica Editora, 2016.

Luiz MOTT; Eduardo MICHELS; Paulinho. Grupo Gay da Bahia: mortes violentas de LGBT no Brasil. Relatório, pp. 1-25, 2019. Disponível em: < https://grupogaydabahia.files.wordpress.com/2019/01/relat\%C3\%B3rio-de-crimes-contralgbt-brasil-2018-grupo-gay-da-bahia.pdf $>$. Acessado em 5 de fevereiro de 2019.

MARTINS, Maria D. José. O problema da violência escolar: uma clarificação e diferenciação de vários conceitos com ela relacionados. International Journal of Developmental and Educational Psychology, Badajoz, Espanha, vol. 2, n. 1, 2005, pp. 425-440, 2005. Disponível em: < https://www.redalyc.org/pdf/374/37418106.pdf > Acessado em 10 de fevereiro de 2019.

Vol. 02, N. 01, Jan. - Mar., 2019 · www.revistas.unilab.edu.br/index.php/rebeh 
MILLET, Kate. "Teoria de la política sexual”. In; Política Sexual. México, DF (Publicado originalmente em New York por Avon, em 1971.), pp.1-34, 1975.

MISKOLCI, Richard. Teoria Queer: um aprendizado pelas diferenças. Belo Horizonte: Autêntica Editora, 2012.

NASCIMENTO, Márcio Neman do. Homofobia e homofobia interiorizada: produções subjetivas de controle heteronormativo? Athenea Digital Londrina, n. 17: 227-239, março, 2010. Disponível em: < https://atheneadigital.net/article/view/n17-nascimento/652-pdf-pt >. Acessado em 10 de fevereiro de 2019.

SCOTT, Joan. Gênero: uma categoria útil de análise histórica. In: Educação e Realidade, p. 71-99, jul./dez, $1995 . \quad$ Disponível em: https://seer.ufrgs.br/educacaoerealidade/article/view/71721/40667 $>$ Acessado em 8 de fevereiro de 2019.

SILVA, Tomaz Tadeu da. Identidade e diferença - a perspectiva dos estudos culturais. $15^{\mathrm{a}}$ ed - Petrópolis: Vozes, 2012. Disponível em: < http://www.diversidadeducainfantil.org.br/PDF/A $\% 20$ produ $\% \mathrm{C} 3 \% \mathrm{~A} 7 \% \mathrm{C} 3 \% \mathrm{~A} 3 \mathrm{o} \% 20$ social $\%$ $20 \mathrm{da} \% 20$ identidade $\% 20 \mathrm{e} \% 20 \mathrm{da} \% 20$ diferen $\% \mathrm{C} 3 \% \mathrm{~A} 7 \mathrm{a} \% 20 \% 20$ Tomaz $\% 20$ Tadeu $\% 20 \mathrm{da} \% 20$ Silva.pdf $>$. Acessado em 8 de fevereiro de 2019.

SMITH, Peter K. Intimidação por colegas e maneiras de evitá-la. In E. Debarbieux \& C. Blaya (Eds.), Violência nas escolas e políticas públicas, Brasília DF: Unesco, pp. 187-205, 2002.

SPOSITO, Marília Pontes. Um breve balanço da pesquisa sobre violência escolar no Brasil. Educação e Pesquisa, São Paulo, v.27, n.1, p. 87-103, jan./jun. 2001. Disponível em: < http://www.scielo.br/pdf/ep/v27n1/a07v27n1.pdf >. Acessado em 9 de fevereiro de 2019.

ZANELLO, Valeska. Saúde mental e gênero: cultura e processos de subjetivação. Curitiba: Appris Editora, 2018.

\title{
SCHOOL BULLYING IN BRAZIL: \\ GENDERED REFLECTIONS AND AN EMERGENCY OF INTERSECTIONAL LIGHTS
}

\begin{abstract}
Bullying began to be studied in Sweden in the 1970s. It is conceptualized as a set of aggressive, physical or psychological behaviors, such as humiliating, kicking, pushing, naming, discriminating, isolating and excluding, occurring in an intentional and repetitive way. In Brazil, where various structures are articulated among themselves, such as racism, homophobia, transphobia, lesbophobia, misogyny, looking at any type of violence without an intersectional proposal may impact on the invisibility of the psychic sufferings of students who are daily traversed by these axes of oppression. If the school has responsibility in the production and development of new citizens for society, bringing in its pedagogical plans the
\end{abstract}


priority in the fight against violence and the promotion of awareness and importance of respect and difference, we need to question which model of education is viable to break with inequality and asymmetries of gender, race, sexuality and other identity markers. The interest in this study is an attempt to understand bullying from a gended and intersectional perspective, questioning national scientific productions that articulate studies on this school phenomenon and gender, mostly with a dichotomous logic of biological sex.

Key words: school bullying, gender, intersectional, race, sexuality.

Recebido em: 11/02/2019

Aceito em: 20/04/2019 
Vol. 02, N. 01, Jan. - Mar., 2018 - www.revistas.unilab.edu.br/index.php/rebeh 